\title{
EARLY CHANGES IN URETEROGRAM AFTER OPERATION ON CANCER OF CERVIX
}

\author{
TAKESHI YAMAGAMI, KOHMEI NISHIO, KUNIKO NAGATA, \\ ATSUICHIRO KUROKAWA, TAKANORI MATSUKUMA \\ AND TOSHI KATO
}
Department of Obstetrics and Gynecology, Kurume University School of Medicine, Kurume, 830, Japan

(Received for publication July 1, 1977)

Day-to-day observations were made on the ureterograms after extensive hysterectomy in cancer of the cervix to reach the conclusion as follows.

(1) Combined use of X-ray television is advantageous in detecting ureteral impairment after operation on cancer of the cervix.

(2) Ureteral impairment after operation on cancer of the cervix starts developing relatively early after operation.

(3) It is 3 to 4 days after operation that the impairment is most severe.

(4) The impairment heads for recovery after the seventh day, but it persists in serious cases.

(5) Judging from the findings above, there is a possibility that the ureteral impairment after operation on cancer of the cervix can be recovered to some extent.

(6) Our impression is that if apreventive step for the ureteral impairment is necessary, carrying it out within seven days will be effective.

\section{INTRODUCTION}

As is generally known, ureteral impairment occurs frequently after operation on cancer of the cervix, and meedless to say, this exerts influence on the kidneys upward and the bladder downward and susequently provides an underlying cause for renal insufficiency (Kato and Yamagami, 1975 ; Shimizu and Yamagami, 1972 ; Shimizu et al., 1973 ; Yamagami, 1972 ; Yamagami et al., 1973 ; Yamagami et al., 1976).

When and how such ureteral impairment occurs have not been clarified yet, which, together with investigation into its cause and the therapeutic question, is of great interest.

Recently, the authors have had an opportunity to make day-to-day observations on ureterogram after operation on cancer of the cervix in 12 cooperative patients, the detalis of which are reported here.

\section{METHODS AND RESULTS}

The ureter makes it a duty to send urine to the bladder from the suprarenal gland and has a function called 


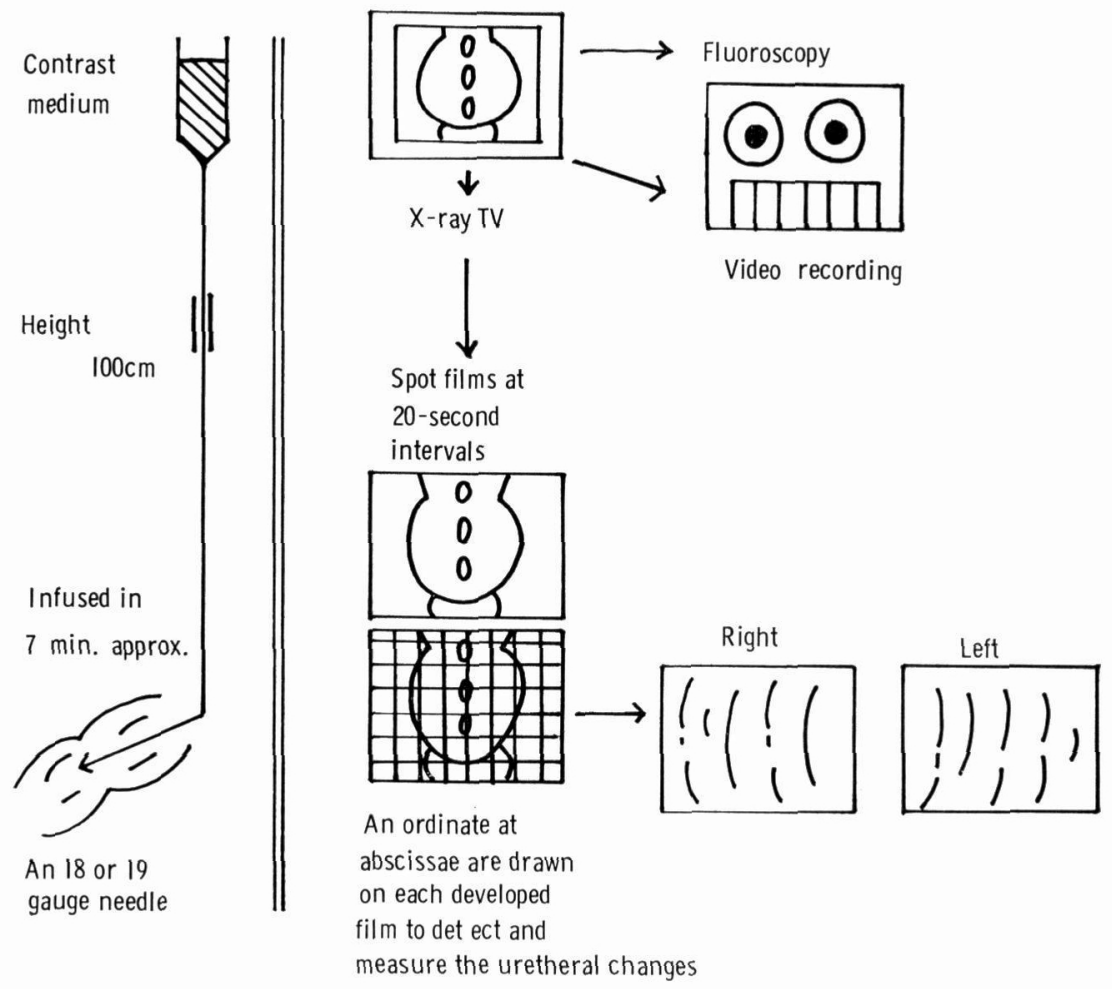

Fig. 1

peristalsis.

In examining the ureteral function, therefore, attention has to be paid not only to how urine passes through it but also on peristalsis.

In Fig. 1 is shown the method. Its details and the method for observations are omitted here since they were reported previously.

\section{PRESENTATION OF REPRESEN- TATIVE CASES, RESULTS AND DISCUSSION}

Photo 1 shows ureteral findings immediately after simple total hysterectomy. To the right of the photo. is shown a measuring diagram.

The ureter on the right remains unchanged in size and the patterns are

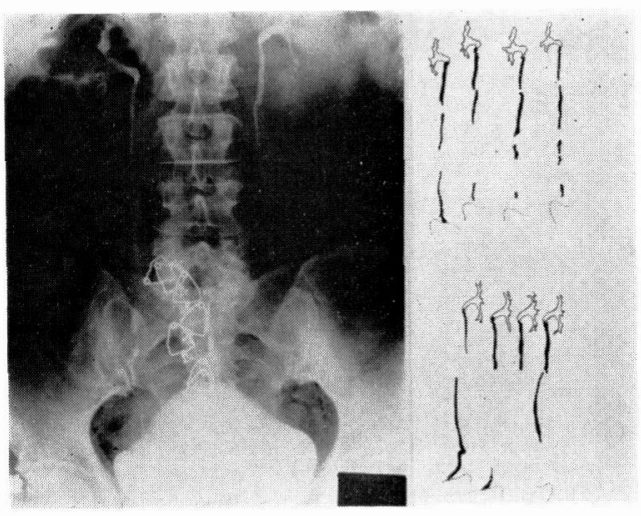

Photo 1

seen appearing in fragments, indicating that the peristalsis is active.

Special findings such as flexion and stricture are not observed here. 

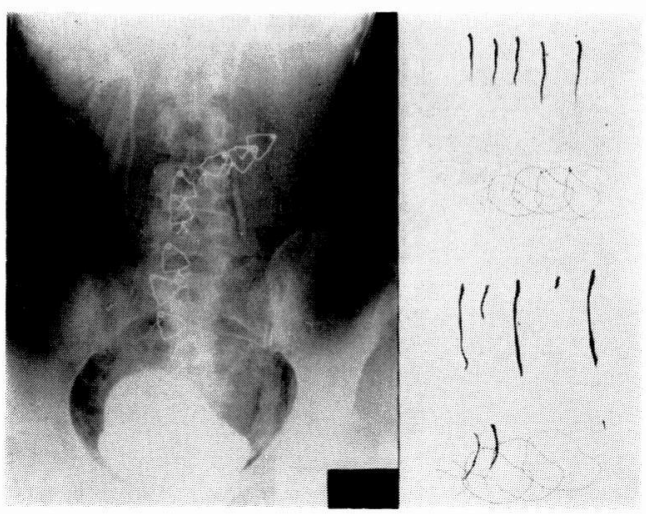

Photo 2

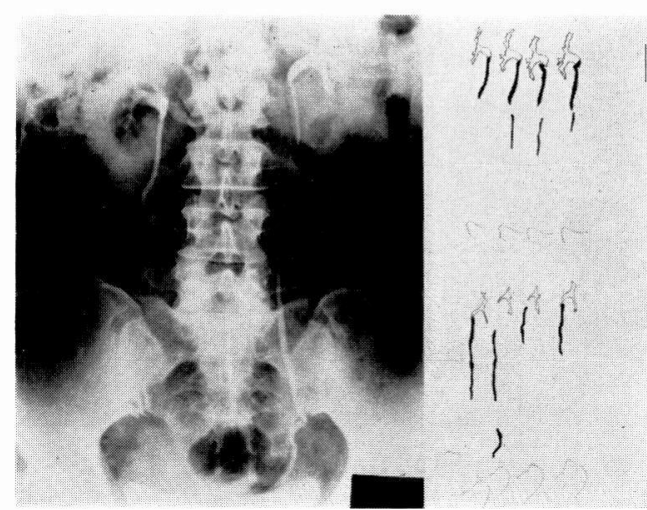

Photo 3

As for the ureter on the left, an identical pattern is seen appearing continually in the upper ureter ; the pace of the pattern appearing is slow in the lower ureter. Furthermore, a pattern of flexion is seen partially but it is not of the fixed type.

Photo 2 shows cancer of the cervix immediately after extensive total hysterectomy.

On the upper right, an identical pattern appears and there is observed a decline of peristalsis.

On the left, a similar tendency is found, but peristalsis is more active than on the right.

Both sides do not show any abnormal findings such as stricture.

When the two above are compared to each other, changes immediately after surgical operation are very slight in both simple hysterectomy and extensive total hysterectomy; and the decline of peristalsis observed more or less immediately after extensive total hysterectomy is considered attributable to the operation time and anesthesia time.

Photo 3 indicates the above-mentioned case, the one on the third day of simple hysterectomy.

A slight decline of peristalsis is seen in the upper right. Flexion is found


fixed type either.

As is clear from the above, there is not much difference between findings on the third day of simple hysterectomy and those immediately after operation, and this technique exerts little influence on the ureteral function.

Photo 4 concerns the case on the third day of extensive total hysterectomy.

It differs from the findings on the third day of simple total hysterectomy mentioned above in that the ureter is swollen and that stricture at the entrance to the bladder is found on the right.

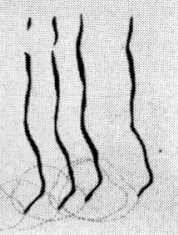

Photo 4 

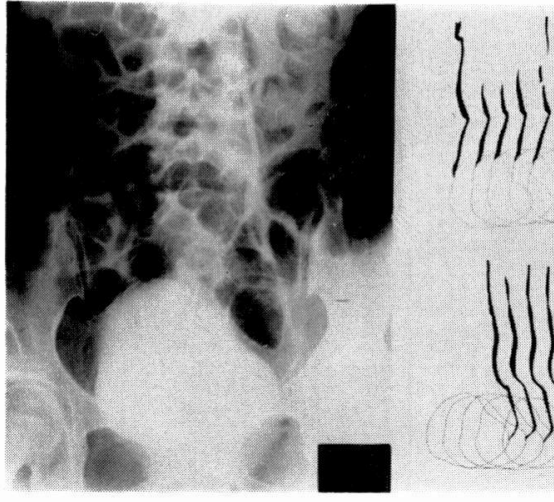

Photo 5

Furthermore, a decline of peristalsis is also present since the entire course of the ureter is cleary seen.

Photo 5 shows the same case on the six day after extensive total hysterectomy.

A stricture pattern is seen on the right and a decline of peristalsis on the left. This gives an impression that the ureteral impairement worsened compared with findings on the third day of the same operation.

Photo 6 shows the same case on the eighth day after extensive total hysterectomy. Compared with the findings on the sixth day, structure is not observed on the right and the peristalsis


Photo 6
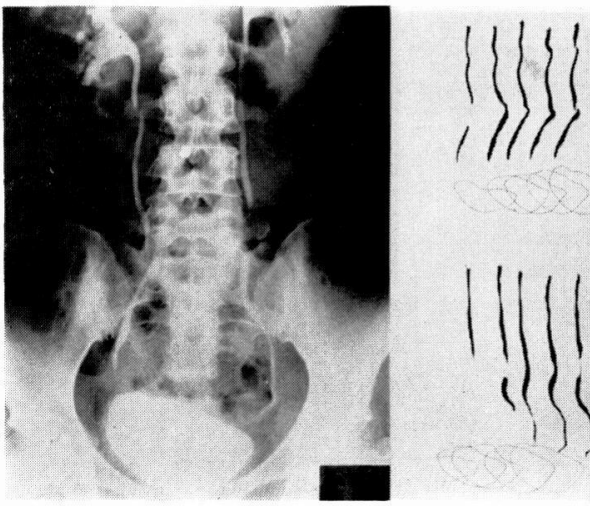

Photo 7

remains low on the left.

On the whole, however, the impairment is milder than the findings observed on the sixth day and the patient appears to be heading for recovery.

Photo 7 indicates the same case on the 19th day after extensive total hysterectomy.

While a decline of peristalsis is observed in the ureters on both sides, abnormal findings such as swelling, flexion and stricture are absent.

Overall impression is similar to that of the eighth day.

In Table 1 is compiled the results of experiments performed as above. Observations were made on 12 cases. It was found that ureteral impairment is hardly observed immediately after extensive total hysterectomy but starts from 24 hours after and develops frequently on the $3 \mathrm{rd}$ and 4 th day according to the statistics.

Thereafter these impairments recover gradually, but abnormality in peristalsis persists up to around the seventh day in many cases.

Abnormal findings such as flexion, swelling and stricture head for recovery after the fourth day if they are reversible, but they persist if the impairment is severe.

Of many cases of ureteral impair- 
TABLE 1

Changes in ureterogram after operation

\begin{tabular}{|c|c|c|c|c|c|c|c|c|}
\hline & \multirow{2}{*}{ Cases } & \multirow{2}{*}{$\begin{array}{c}\text { Sides } \\
\text { examind }\end{array}$} & \multirow{2}{*}{ Tortuosty } & \multirow{2}{*}{ Dilatation } & \multirow{2}{*}{ Stricture } & \multicolumn{2}{|c|}{ Peristaltic motility } & \multirow{2}{*}{$\begin{array}{l}\text { Look of } \\
\text { opacifica- } \\
\quad \text { tion }\end{array}$} \\
\hline & & & & & & Decreased & Increased & \\
\hline $\begin{array}{l}\text { Immediately } \\
\text { after opera- } \\
\text { tion }\end{array}$ & 12 & 24 & $1 / 24$ & $1 / 24$ & $1 / 24$ & $20 / 24$ & $0 / 24$ & $0 / 24$ \\
\hline $\begin{array}{l}\text { 1st day } \\
\text { post op. }\end{array}$ & 12 & 24 & $3 / 24$ & $5 / 24$ & $5 / 24$ & $20 / 24$ & $0 / 24$ & $0 / 24$ \\
\hline $\begin{array}{l}\text { 2nd day } \\
\text { post op. }\end{array}$ & 10 & 20 & $3 / 20$ & $4 / 20$ & $4 / 20$ & $18 / 20$ & $0 / 24$ & $0 / 24$ \\
\hline $\begin{array}{l}\text { 3rd day } \\
\text { post op. }\end{array}$ & 10 & 20 & $3 / 20$ & $7 / 20$ & $7 / 20$ & $18 / 20$ & $0 / 20$ & $0 / 20$ \\
\hline $\begin{array}{l}\text { 4th day } \\
\text { post op. }\end{array}$ & 10 & 20 & $3 / 20$ & $7 / 20$ & $7 / 20$ & $18 / 20$ & $0 / 20$ & $0 / 20$ \\
\hline $\begin{array}{l}5 \text { th day } \\
\text { post op. }\end{array}$ & 10 & 20 & $3 / 20$ & $3 / 20$ & $3 / 20$ & $18 / 20$ & $0 / 20$ & $0 / 20$ \\
\hline $\begin{array}{l}6 \text { th day } \\
\text { post op. }\end{array}$ & 10 & 20 & $3 / 20$ & $3 / 20$ & $3 / 20$ & $18 / 20$ & $0 / 20$ & $0 / 20$ \\
\hline $\begin{array}{l}\text { 7th day } \\
\text { post op. }\end{array}$ & 10 & 20 & $3 / 20$ & $3 / 20$ & $3 / 20$ & $9 / 20$ & $0 / 20$ & $0 / 20$ \\
\hline $\begin{array}{l}\text { 8th day } \\
\text { post op. }\end{array}$ & 8 & 16 & $3 / 20$ & $3 / 20$ & $3 / 20$ & $6 / 20$ & $0 / 20$ & $0 / 20$ \\
\hline $\begin{array}{l}\text { 9th day } \\
\text { post op. }\end{array}$ & 8 & 16 & $3 / 20$ & $3 / 20$ & $3 / 20$ & $6 / 20$ & $0 / 20$ & $0 / 20$ \\
\hline $\begin{array}{l}\text { 14th day } \\
\text { post op. }\end{array}$ & 12 & 24 & $3 / 20$ & $3 / 20$ & $3 / 20$ & $4 / 20$ & $1 / 20$ & $0 / 20$ \\
\hline $\begin{array}{l}62 \text { th day } \\
\text { post op. }\end{array}$ & 12 & 24 & $3 / 20$ & $3 / 20$ & $3 / 20$ & $3 / 20$ & $1 / 20$ & $0 / 20$ \\
\hline
\end{tabular}

ment the authors have so far observed, there were certainly some cases that attained recovery from two weeks after the surgical operation, but that was not observed with the twelve cases presented in this paper.

\section{REFERENCES}

Kato, T. and Yamagami, T. (1975). A study on treatment of carainoma of the uterine cervix and associated ureteral disorders.

Kurume Med. J., 22, 79-101.

Shimizu, N. and Yamagami, T. (1972). Treatments of cancer of the uterus, discussed fom the viewpoint of the ureter. J. Jap. Cancer Th., 7, 1-16.
Shimizu, N., Yamagami, T., Nagamatsu, K. and HASHIMURA, T. (1973). On the relationship between ureteral lesion and prognosis of cervical cancer. J. Jap. Cancer Th., 8, 61-68.

YAMAGAMI, T. (1972). The prognosis of cervical cancer. Panal discussion report at the 24th general meeting of the Japanese Society of Obstetrics and Gynecology at Okayama, Japan on April 16.

Yamagami, T., Ide, K., Umezu, J. and Kato, T. (1973). Studies on the pathophysiology of ureteral lesion in treatment for the uterine cervical cancer. Kurume Med. J., 20, 113-118.

Yamagami, T., Nishio, K., Nishimura, H., Matsukuma, T. and Kato, T. (1976). Supplemental studies on the treatment of uterine cervical and ureteral disturbance based on a statical analysis. 